\title{
The Effect of Using Blue Light Filter Feature on Smartphones with Asthenopia Occurrence
}

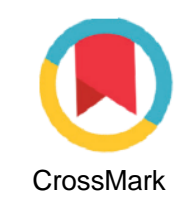

Arnan Victor Wiryawan ${ }^{1}$, Maharani $^{2}$, Tanti Ajoe Kesoema ${ }^{3}$, Riski Prihatningtias ${ }^{2 \star}$

\author{
${ }^{1}$ Student of Faculty of Medicine, Diponegoro University, Semarang, Indonesia \\ ${ }^{2}$ Department of Ophthalmology, Faculty of Medicine, Diponegoro University, Semarang, Indonesia \\ ${ }^{3}$ Department of Physical Medicine and Rehabilitation, Faculty of Medicine, Diponegoro University, Semarang, Indonesia
}

Keywords:
Asthenopia
Blue light
Blue light filter
Smartphone

*) Correspondence to: riskiprihatningtias@gmail. com

Article history:

Received 15-12-2020

Accepted $04-02-2021$

Availableonline10-03-2021

\begin{abstract}
Background: Smartphone users can be found in almost every class society in Indonesia. Excessive use of smartphones and the blue light emitted by smartphones play an important role in causing asthenopia symptoms. Smartphone development companies have developed a blue light filter feature, which is expected to reduce the incidence of Asthenopia symptoms.

Objective: To evaluate the Asthenopia questionnaire's comparison results before and after smartphone use with various levels of opacity in the blue light filter.

Methods: This study used a quasi-experimental pre-posttest study. The research subjects were students of the Faculty of Medicine, Diponegoro University $(n=30)$, selected by purposive sampling. In this study, research subjects saw an hour-long smartphone with a predetermined opacity level for the blue light filter, with the same room lighting. Before and after the treatment, the subjects were asked to fill out the Asthenopia questionnaire. Data were analyzed using the Wilcoxon test, Mann Whitney U test, and Kruskal Wallis test.

Results: The results of the Asthenopia questionnaire before and after using a smartphone with a blue light filter opacity level of $0 \%$ and $100 \%$ showed a significant difference in results $(\mathrm{p}<0.05)$, and there was no significant difference for the preposttest using a smartphone with a blue light filter with $50 \%$ opacity level. The comparison results of the Asthenopia questionnaire between smartphone use with the opacity level of the blue light filter $0 \%$ and $50 \%$ only showed a significant difference in sore/aching eye symptoms. The comparison results of the Asthenopia questionnaire between smartphone use with the opacity level of the blue light filter $50 \%$ and $100 \%$ only showed a significant difference in sleepy eye symptoms. The comparison results of the Asthenopia questionnaire between smartphone use with the opacity level of the blue light filter $0 \%, 50 \%$, and 100\%, did not show a significant difference.

Conclusion: There were no significant differences between the Asthenopia questionnaire results with $0 \%, 50 \%$, and $100 \%$ opacity blue light filters after one hour of smartphone use.
\end{abstract}

DIMJ, 2021, 2(1), 30-35 DOI: https:// doi.org/10.14710/dimj.v2i1.9761

\section{Introduction}

The statistical survey states that smartphone users in Indonesia have increased from 11.7 million in 2011 to 62.69 million in 2017 and are predicted to increase until it reaches 89.86 million in 2022. As a result of the increasing number of smartphone features, the length of time smartphones used has also increased. Where in previous studies, it was stated that the length of time using a smartphone for more than 1 hour could reach $35.6 \%$ of the total sample population studied with various uses such as studying, watching movies, playing games, and opening social media. ${ }^{9-12}$ The usage time of smartphones, which nowadays tend to be long, has a considerable effect on the body. In previous studies, it was stated that in addition to having an effect on neck and shoulder pain, intensive smartphone use would also cause visual disturbances symptoms. These symptoms are related to screen size, small writing, the use of smartphones in dark places, and the tendency to focus when looking at the smartphone screen, which affects the visual organ's workload. ${ }^{13}$

Eye fatigue symptoms are closely related to the blue light emitted by the light-emitting diode (LED) 
(LED) on the smartphone screen. Even though it looks like white light, the light emitted by a lightemitting diode (LED) has a 400 - $490 \mathrm{~nm}$ wavelength, which falls into the blue light category. Eye fatigue symptoms that are influenced by the use of digital devices or commonly referred to as digital eye strain (DES) have a reasonably high prevalence due to the increasing number of smartphone users in the world. In previous studies, it was stated that the amount could reach $65 \%$ of every 10.000 populations in the United States. ${ }^{1,4,8}$

In previous studies, many found an association between the duration of smartphone use for 1 hour and the incidence of asthenopia. Some studies stated that asthenopia symptoms improve significantly a few minutes close to 1 hour after using smartphones or tablets. Previous research has also examined various efforts to reduce the effects of blue light on prolonged smartphone use on eye health, from wearing glasses equipped with blue-blocking (BB) filters or neutral-density (ND) filters to using intraocular lenses (IOL) coated with a blue light filter. Apart from using additional tools to reduce the effects of blue light emission, today's smartphones are mostly equipped with features that will eliminate some of the blue light resulting in a yellowish smartphone screen. This study was conducted to prove how the use of the blue-light filter feature on smartphones affects the incidence of asthenopia. ${ }^{5,6,13}$

\section{Methods}

This research used a quasi-experimental preposttest study design. The research was conducted over three weeks during September 2020.

The research subjects were students of the Faculty of Medicine University Diponegoro, with a total sample of 30 selected by purposive sampling, which met the exclusion and inclusion criteria. The inclusion criteria for research subjects are 19-22 years old, students of the Faculty of Medicine Diponegoro University, willing to be a research subject, and have smartphones with AMOLED screens and IPS LCD. In contrast, this study's exclusion criteria were suffering from certain eye diseases such as diabetes mellitus, hypertension, Sjogren's syndrome, wearing contact lenses, wearing glasses, using drugs such as antidepressants, antibiotics, antihistamines, stimulants, antihypertensives, hormone therapy, and steroids.

In this study, the research subjects were treated using a smartphone with the opacity level of the blue light filter that had been determined in each group. Subjects looked at the smartphone for one hour with a $30 \mathrm{~cm}$ distance from the eye to the smartphone.
Before and after treatment using a smartphone, the quality of the subject's asthenopia symptoms was measured using a questionnaire on the severity of asthenopia symptoms experienced by the research subject.

The independent variable in this study is the opacity level of the smartphone's blue light filter, while the dependent variable in this study is the result of the asthenopia questionnaire. Hypothesis testing to compare pre and post-test after smartphone use has been carried out by the Wilcoxon test. Meanwhile, the Mann-Whitney $U$ test was used to test the hypothesis to compare the two independent variables and to test the hypothesis comparing the three independent variables at the same time by the Kruskal Wallis test.

\section{Results}

The research data will be processed statistically to determine whether there is a significant difference in the pre-post asthenopia symptoms for each blue light filter opacity level, and the comparison results of the post-test asthenopia symptoms comparison in each opacity level. The results of statistical data analysis can be seen in the following table.

Table 1. Comparison of asthenopia questionnaire results between pre and post-test in various blue light filter opacity levels

\begin{tabular}{|c|c|c|c|}
\hline \multirow{2}{*}{$\begin{array}{l}\text { Asthenopia } \\
\text { Symptoms } \\
\text { p-value }\end{array}$} & \multicolumn{3}{|c|}{ Pre-Posttest Group } \\
\hline & $\begin{array}{l}\text { Blue light } \\
\text { filter } 0 \%\end{array}$ & $\begin{array}{l}\text { Blue light } \\
\text { filter } 50 \%\end{array}$ & $\begin{array}{l}\text { Blue light } \\
\text { filter } 100 \%\end{array}$ \\
\hline Tired eye & $0,026^{W *}$ & $0,024^{W *}$ & $0,054^{W}$ \\
\hline $\begin{array}{l}\text { Sore/aching } \\
\text { eye }\end{array}$ & $0,007^{W *}$ & $0,102^{W}$ & $0,041^{\# *}$ \\
\hline Irritated eye & $0,042^{W *}$ & $0,109^{\#}$ & $0,414^{\#}$ \\
\hline Watery eye & $0,037^{W *}$ & $0,774^{\#}$ & $0,084^{\#}$ \\
\hline Dry eye & $0,027^{W *}$ & $0,026^{\varpi *}$ & $0,058^{\#}$ \\
\hline Sleepy eye & $0,257^{\#}$ & $0,863^{\#}$ & $0,010^{\# *}$ \\
\hline $\begin{array}{l}\text { Hot/burning } \\
\text { eye }\end{array}$ & $0,010^{\# *}$ & $0,581^{W}$ & $0,102^{\#}$ \\
\hline $\begin{array}{l}\text { Blurred } \\
\text { vision }\end{array}$ & $0,102^{W}$ & $0,655^{\#}$ & $0,915^{\#}$ \\
\hline $\begin{array}{l}\text { Difficulty } \\
\text { in focusing }\end{array}$ & $0,414^{W}$ & $0,705^{W}$ & $0,783^{\#}$ \\
\hline $\begin{array}{l}\text { Visual } \\
\text { discomfort }\end{array}$ & $0,034^{W *}$ & $0,168^{W}$ & $0,041^{\# *}$ \\
\hline Total Score & $0,005^{\mathrm{W} *}$ & $0,066^{\#}$ & $0,028^{\# *}$ \\
\hline
\end{tabular}

At the $0 \%$ opacity level of the blue light filter, the Wilcoxon test was carried out, and there was a significant difference $(\mathrm{p}<0.5)$ from the symptoms of eye fatigue, pain, irritation, wateriness, dryness, 
heat/burning, eye discomfort, and the total score between pre and post-test Asthenopia Symptoms Questionnaire. However, there were no significant differences in the eye symptoms of drowsiness, blurry, and difficulty in focusing ( $p>0.5)$ (Table 1).

There was a significant difference in the Wilcoxon test for the blue light filter's $50 \%$ opacity level $(\mathrm{p}<0.5)$ between the pre and post-test Asthenopia symptoms questionnaire. However, eye pain, irritation, wateriness, drowsiness, burning/burning, blurred, difficulty focusing, discomfort, and the total score did not show any significant differences $(\mathrm{p}>0.5)$ (Table 1$)$.

In the Wilcoxon test for the blue light filter's opacity level $100 \%$, there was a significant difference $(\mathrm{p}<0.5)$ between the pre and post-test Asthenopia symptom questionnaire. However, there were no significant differences in the eye symptoms of tiredness, irritation, wateriness, dryness, burning/burning, blurred, difficulty focusing ( $p>0.5)$ (Table 1).

Table 2. Comparison between asthenopia questionnaire post test results and two blue light filter opacity levels

\begin{tabular}{|c|c|c|c|}
\hline \multirow[b]{2}{*}{$\begin{array}{l}\text { Asthenopia } \\
\text { Symptoms } \\
\text { p-value }\end{array}$} & \multicolumn{3}{|c|}{ Post-test Group } \\
\hline & $\begin{array}{l}\text { Blue light } \\
\text { filter } 0 \% \\
\text { and } 50 \%\end{array}$ & $\begin{array}{l}\text { Blue light } \\
\text { filter } 0 \% \\
\text { and } 100 \%\end{array}$ & $\begin{array}{l}\text { Blue light } \\
\text { filter } 50 \% \\
\text { and } 100 \% \\
\end{array}$ \\
\hline Tired eye & $0,392^{t}$ & $0,259^{t}$ & $0,726^{+}$ \\
\hline $\begin{array}{l}\text { Sore/aching } \\
\text { eye }\end{array}$ & $0,040^{* *}$ & 0,204 & $0,441^{+}$ \\
\hline Irritated eye & $0,155^{\ddagger}$ & $0,298^{+}$ & $0,801^{\ddagger}$ \\
\hline Watery eye & $0,061^{\dagger}$ & $0,089^{*}$ & $0,579^{*}$ \\
\hline Dry eye & $0,907^{\ddagger}$ & $0,726^{\ddagger}$ & $0,816^{\ddagger}$ \\
\hline Sleepy eye & $0,350^{\ddagger}$ & $0,203^{\ddagger}$ & $0,026^{+*}$ \\
\hline $\begin{array}{l}\text { Hot/burning } \\
\text { eye }\end{array}$ & $0,269^{\ddagger}$ & $0,079^{\ddagger}$ & $0,505^{\ddagger}$ \\
\hline $\begin{array}{l}\text { Blurred } \\
\text { vision }\end{array}$ & $0,184^{\dagger}$ & $0,524^{\dagger}$ & $0,467^{*}$ \\
\hline $\begin{array}{l}\text { Difficulty in } \\
\text { focusing }\end{array}$ & $0,330^{\ddagger}$ & 0,969 & $0,327^{+}$ \\
\hline $\begin{array}{l}\text { Visual } \\
\text { discomfort }\end{array}$ & $0,278^{\dagger}$ & $0,818^{\ddagger}$ & $0,354^{\ddagger}$ \\
\hline Total Score & $0,185^{\dagger}$ & $0,426^{\ddagger}$ & $0,519^{+}$ \\
\hline
\end{tabular}

From the comparison between the post-test opacity level of $0 \%$ blue light filter and $50 \%$ using the Mann Whitney test, it was found that there was a significant difference $(p<0.05)$ in the symptoms of eye pain. However, there was no significant difference in other eye symptoms such as tired, irritated, watery, dry, drowsy, hot/burning, blurred, difficult to focus, uncomfortable, and the total score (p>0.05) (Table 2).

From the comparison between the post-test opacity level of $0 \%$ blue light filter and $100 \%$ using the Mann Whitney test, there was no significant difference ( $p>0.05$ ) in eye symptoms of fatigue, pain, irritation, wateriness, dryness, drowsiness, heat/burning, blurred, hard to focus, uncomfortable, and the total score (Table 2).

From the comparison between the post-test the opacity level of the blue light filter 50\% and 100\% using the Mann Whitney test, there was a significant difference $(p<0.05)$ in drowsiness symptoms. However, there were no significant differences in other eye symptoms such as fatigue, pain, irritation, wateriness, dryness, hot / burning, blurred, difficulty focusing, discomfort, and the total score ( $p>0.05$ ) (Table 2).

Table 3. Comparison of asthenopia questionnaire post test results between blue light filter $0 \%, 50 \%$, and $100 \%$ opacity level

\begin{tabular}{lc}
\hline \multirow{2}{*}{$\begin{array}{c}\text { Asthenopia Symptoms } \\
\text { p-value }\end{array}$} & \begin{tabular}{c} 
Post-test Group \\
\cline { 2 - 2 } Tired eye
\end{tabular} \\
$\begin{array}{c}\text { Blue light filter } 0 \%, 50 \%, \\
\text { and } 100 \%\end{array}$ \\
Sore/aching eye & $0,488^{\mathrm{K}}$ \\
Irritated eye & $0,111^{\mathrm{K}}$ \\
Watery eye & $0,337^{\mathrm{K}}$ \\
Dry eye & $0,106^{\mathrm{K}}$ \\
Sleepy eye & $0,943^{\mathrm{K}}$ \\
Hot/burning eye & $0,080^{\mathrm{K}}$ \\
Blurred vision & $0,194^{\mathrm{K}}$ \\
Difficulty in focusing & $0,407^{\mathrm{K}}$ \\
Visual discomfort & $0,532^{\mathrm{K}}$ \\
Total Score & $0,498^{\mathrm{K}}$ \\
\hline Intormation: ${ }^{\mathrm{K}}$ Kruskal Wallis, & $0,387^{\mathrm{K}}$ \\
\hline
\end{tabular}

Information: ${ }^{K}$ Kruskal Wallis, * Significant $(\mathrm{p}<0,05)$

In the Kruskal Wallis test to compare the results of the Asthenopia post-test questionnaire with the opacity level of the blue light filter $0 \%, 50 \%$, and $100 \%$, there was no significant difference ( $p>0.05)$ from the symptoms of tired, painful, irritated, watery, dry eyes, drowsiness, burning/burning, blurry, difficulty focusing, discomfort, and the total score (Table 3)

\section{Discussion}

The results of the pre and post-test comparison of the Asthenopia questionnaire in the group that using a blue light filter opacity of $0 \%$ showed that in 
the Wilcoxon test, it was found that there were significant differences in most of the asthenopia symptoms and the total score. This can happen because the continuous use of a smartphone for one hour will cause asthenopia symptoms associated with digital eye strain (DES). In previous studies, it was stated that the symptoms associated with asthenopia appeared significantly closer to one hour of smartphone use. Exposure to blue light causes phototoxicity and oxidative stress so that the use of a smartphone for one hour continuously without pause can cause various symptoms of asthenopia. ${ }^{1,2,3}$

In the group using a blue light filter opacity by $50 \%$, the Wilcoxon test result that was used to compare the pre and post-test results showed no significant difference in most asthenopia symptoms and the total score. This can happen because a blue light filter is applied to the smartphone screen and affects the blue light level entering the eye, thereby reducing symptoms related to digital eye strain (DES). There is a significant difference in the symptoms of tired eyes and dry eyes, and this is following previous studies that state that the highest prevalence of asthenopia symptoms that appear in individuals using gadget devices are symptoms of tired eyes and dry eyes. ${ }^{4,5,6}$

In the group using a blue light filter opacity by $100 \%$, there was no significant difference in most of the asthenopia symptoms and the Wilcoxon test's total score, which was used to compare the pre and post-test results. This can happen because a blue light filter is applied to the smartphone screen and affects the blue light level entering the eye, thereby reducing symptoms related to digital eye strain (DES). There was a significant difference in eye pain, drowsiness, and discomfort. This can occur due to the use of a $100 \%$ blue light filter, the percentage of blue light is reduced a lot, and the smartphone screen becomes yellowish, which encourages the eyes to tend to be sleepy but is still forced to wake up so that these symptoms arise. ${ }^{5,6,7}$

The results from comparing the differences in the post-test of Asthenopia questionnaire on smartphone use with a blue light filter opacity level of $0 \%$ and $50 \%$ showed no significant difference. However, there is a significant difference in the symptoms of eye pain, this indicates a significant reduction in eye pain symptoms after the use of the blue light filter feature as much as $50 \%$, so it can be said that $50 \%$ blue light filter has a significant effect on reducing eye pain symptoms after using a smartphone for an hour. $5,6,8$

From the study, it was also found that there was no significant difference in the post-test results of the Asthenopia questionnaire after using a smartphone with a blue light filter of $0 \%$ and $100 \%$ opacity. According to previous research, this can happen because asthenopia symptoms began to appear significantly in the minutes approaching one hour and will continue to rise in the following minutes. From the study, it was also found that there was a change in dry eye symptoms, although after a statistical test was carried out, there was no significant difference. This can happen because even though $100 \%$ of the blue light filter has been used, the eyes still tend to focus and accommodate continuously on the smartphone screen, which results in reduced blinking frequency resulting in dry eyes. ${ }^{1,2,9}$

The results obtained from the study on the posttest Asthenopia questionnaire after using a smartphone with a blue light filter opacity of $50 \%$ and $100 \%$ showed no significant difference. However, there was a significant difference in the symptoms of drowsiness. This indicates a significant increase in drowsiness eye symptoms after using the blue light filter feature as much as $100 \%$ compared to the use of the blue light filter feature as much as $50 \%$, which is due to the color of the screen when using the blue light filter feature as much as $100 \%$ tends to be yellow. Resulting in makes the eyes' drowsiness and forces the individual to keep staring at the smartphone screen, increasing the load given to the eye so that other symptoms arise. ${ }^{10}$

The results of the Kruskal-Wallis statistical test comparing the post-test results of the Asthenopia questionnaire between treatments using a smartphone for one hour in the opacity level blue light filter group $0 \%, 50 \%$, and $100 \%$ showed that there was no significant difference in each asthenopia symptom individually or on the total score.

In previous studies, it was stated that asthenopia's incidence increased significantly at the end of 60 minutes during its use and continued to increase over time. In their study, Kim et al. also mentioned that using a smartphone for more than two hours can have a significant adverse effect on eye health. ${ }^{1,2}$

Blue light has a wavelength between 450-490 $\mathrm{mm}$, close to the wavelength of ultraviolet light. Even though it looks white, long-term exposure to blue light can cause significant damage to the cornea and retina due to its role in inducing phototoxicity and oxidative stress. Besides, the habit of focusing the eyes when looking at a smartphone will make the eyes accommodate and converge continuously, which will also make the frequency of blinking decrease, thus exacerbating asthenopia symptoms. ${ }^{1,3,8}$

The reason there is no significant difference between the results of the Asthenopia questionnaire and the opacity level of the blue light filter of $0 \%$, 
$50 \%$, and $100 \%$ is that this study was conducted with a duration of one hour where asthenopia symptoms appeared significantly in the final minutes approaching 60 minutes and would increase with time. As a result, data retrieval at the end of the 60th minute tends to still not produce drastically different data.

The limitation in this study is that the researcher cannot control confounding variables such as measuring the number of eye blinks of the research subject, still used two types of smartphone screens in this study, and researchers also do not equalize the activities that carried out when using a smartphone. This will affect the study results because there are activities that require high eye concentration, such as playing video games, but there are also activities that tend to be relaxed, such as opening applications that contain pictures and writing. Activities that require high eye concentration are more likely to induce asthenopia symptoms. ${ }^{1,8}$

\section{Conclusion}

The mean Based on the data presentation and the discussion that has been presented, it can be concluded that there were no significant differences in the Asthenopia questionnaire results before and after using the smartphone for one hour with the opacity level of the blue light filter of $0 \%, 50 \%$, and $100 \%$. The differences of Asthenopia questionnaire results after treatment between opacity levels of $0 \%$, $50 \%$, and $100 \%$ of the blue light filter were also not significant.

\section{Ethical Approval}

This research has obtained ethical approval from the Medical and Health Research Ethics Commission (KEPK), Faculty of Medicine, Diponegoro University with Number 192 / EC / KEPK / FKUNDIP / VIII / 2020.

\section{Conflicts of Interest}

The authors declare no conflict of interest.

\section{Funding}

No specific funding was provided for this article.

\section{Author Contribution}

Writing-original draft preparation, Arnan Victor Wiryawan; Writing-review and editing, dr. Riski Prihatningtias, Sp.M(K).

\section{Acknowledgments}

This work was supported by Department of Ophthalmology, Faculty of Medicine, Diponegoro University.

\section{References}

1. Long J, Cheung R, Duong S, Paynter R, Asper L. Viewing distance and eyestrain symptoms with prolonged viewing of smartphones. Clin Exp Optom. 2017;100(2):133-7.

2. Kim J, Hwang Y, Kang S, Kim M, Kim TS, Kim $\mathrm{J}$, et al. Association between Exposure to Smartphones and Ocular Health in Adolescents. Ophthalmic Epidemiol [Internet]. 2016 Jul 3 [cited 2020 Mar 15];23(4):269-76.

3. Zhao ZC, Zhou Y, Tan G, Li J. Research progress about the effect and prevention of blue light on eyes. Int $\mathrm{J}$ Ophthalmol. 2018;11(12):1999-2003.

4. Sheppard AL, Wolffsohn JS. Digital eye strain: prevalence, measurement and amelioration. BMJ open Ophthalmol [Internet]. 2018 Apr 16;3(1):e000146-e000146.

5. Downie LE, Busija L, Keller PR. Blue-light filtering intraocular lenses (IOLs) for protecting macular health. Cochrane Database Syst Rev. 2018;2018(5).

6. Palavets T, Rosenfield M. Blue-blocking Filters and Digital Eyestrain. Optom Vis Sci. 2019;96(1):48-54.

7. Blume C, Garbazza C, Spitschan M. Effects of light on human circadian rhythms, sleep and mood [Internet]. Vol. 23, Somnologie. Dr. Dietrich Steinkopff Verlag GmbH and Co. KG; 2019 [cited 2020 Oct 22]. p. 147-56.

8. Kim DJ, Lim C-Y, Gu N, Park CY. Visual Fatigue Induced by Viewing a Tablet Computer with a High-resolution Display. Korean J Ophthalmol. 2017;31(5):388.

9. Machmud K. The Smartphone Use in Indonesian Schools: The High School Students' Perspectives. J Arts Humanit. 2018 Mar 30;7:33.

10. Trivedi R. Consumer Purchase Intentions towards Smartphone: A Factorial Study. Int J Adv Res Comput Sci Manag Stud [Internet]. 2018;6(4):40-8.

11. Parasuraman S, Sam AT, Yee SWK, Chuon BLC, Ren LY. Smartphone usage and increased risk of mobile phone addiction: A concurrent study. Int $\mathbf{J}$ Pharm Investig [Internet]. 2017;7(3):125-31.

12. Cha S-S, Seo B-K. Smartphone use and smartphone addiction in middle school students 
in Korea: Prevalence, social networking service, and game use. Heal Psychol open [Internet]. $2018 \mathrm{Feb}$ 2;5(1):20551029187550462055102918755046
13. Antona B, Barrio AR, Gascó A, Pinar A, González-Pérez M, Puell MC. Symptoms associated with reading from a smartphone in conditions of light and dark. Appl Ergon [Internet]. 2018;68(May 2017):12-7. 